\title{
História cultural e história do corpo na História Antiga alemã $\tilde{a}^{*}$
}

\author{
Cultural history and the history of the body in German Ancient History
}

\author{
Jan B. Meister \\ jan.meister@geschichte.hu-berlin.de \\ Humboldt-Universität zu Berlin \\ Institut für Geschichtswissenschaften \\ Unter den Linden 6, D \\ 10099 - Berlin \\ Germany
}

\section{Resumo}

O objetivo deste artigo é explicar as idiossincrasias da História Cultural como praticada na Alemanha - ou melhor, nos países de língua alemã - e chamar a atenção para alguns desenvolvimentos recentes no contexto dessa nova História Cultural entre historiadores alemães da Antiguidade no campo específico da história do corpo. São discutidas várias tendências da História Cultural. Primeiro, que os historiadores foram influenciados pela história da vida cotidiana, que foca em pequenas unidades e em diferentes aspectos da vida comum e não em grandes superestruturas da sociedade. Outra tendência é o crescente interesse de historiadores alemães em métodos e teorias derivados da antropologia cultural. Uma terceira tendência é o crescente interesse na história feminista e especialmente na construção de papéis de gênero. Um caso especial nesse amplo campo da História Cultural é a história do corpo. De certo modo, essa área de especialização da história exemplifica todos os problemas e possibilidades da História Cultural.

\section{Palavras-chave}

História cultural; História do corpo; Historiografia alemã.

\begin{abstract}
This article aims to explain the idiosyncrasies of cultural history as practiced in Germany - or rather the German-speaking world - and to draw attention to some recent developments within the context of this new cultural history among German ancient historians in the specialized field of the history of the body. Several trends of cultural history are discussed. First, historians have been influenced by the history of everyday life, which focuses on small units and different aspects of ordinary life rather than large superstructures of society. Another trend is the growing interest of German historians in methods and theories derived from cultural anthropology. A third trend is the growing interest in feminist history and especially in the construction of gender roles. A special case in this rather broad field of cultural history is the history of the body. To a certain extent, this specialized area of history exemplifies all the problems and opportunities of cultural history.
\end{abstract}

\section{Keywords}

Cultural history; History of the body; German historiography.

Recebido em: 21/4/2013

Aprovado em: 25/6/2013

* Tradução realizada por Fábio Faversani e revisão por Fábio Duarte Joly. 
O objetivo deste artigo é duplo: ${ }^{1}$ primeiro, explicar as idiossincrasias da história cultural como praticada na Alemanha - ou, melhor, no mundo germanófono ${ }^{2}$ - e, em segundo lugar, chamar a atenção para alguns desdobramentos recentes no contexto desta nova história cultural na academia alemã no campo especializado da história do corpo. As idiossincrasias da história antiga alemã podem ser melhor ilustradas quando vistas de fora. Em 1999, Thomas Späth publicou um artigo na renomada revista francesa Annales com o intrigante título: "Nouvelle Histoire Ancienne? Sciences sociales et histoire romaine: à propos de quatre récentes publications allemandes" (SPÄTH 1999). Com este artigo, Späth estava tentando chamar a atenção dos seus colegas franceses para alguns desenvolvimentos recentes na historiografia alemã, que, em sua opinião, poderiam, na verdade, ser vistos como ponto de partida de uma "nova História Antiga". Este artigo foi escrito por duas razões. A primeira é, obviamente, que Späth assumiu - e provavelmente com razão - que a maioria dos estudiosos franceses era incapaz ou não estava interessada em ler as muitas vezes tediosas "Qualifikationsschriften" alemãs e, portanto, desconheciam as novas abordagens adotadas na academia alemã. A segunda razão é que, no início de 1990, algumas mudanças importantes tinham mesmo ocorrido não apenas na história antiga alemã, mas na historiografia alemã como um todo.

Os quatro livros discutidos por Späth são usados para ilustrar essa mudança: eles são bastante diversificados nos temas, mas estão ligados pelos novos métodos que usam e pelas questões que colocam. A "Habilitationsschrift" de 132 Egon Flaig sobre usurpação no início do Principado (FLAIG 1992) busca analisar a história política como história da praxis e centra-se na relevância dos símbolos e rituais. Ao analisar o quadro simbólico que moldou e motivou as ações de diferentes grupos sociais, ele desenvolve uma abordagem completamente nova para a história política. A tese de doutorado de Dirk Barghop "Forum der Angst" (BARGHOP 1994) é o segundo livro discutido por Späth. Contrastando com Flaig, Barghop enfrenta um assunto completamente novo, concentrando-se no medo senatorial como objeto histórico. Fazendo uso extensivo das teorias do sociólogo francês Pierre Bourdieu, seu estudo apresenta não só novos temas, mas também novos métodos para o campo da história antiga. ${ }^{3} \mathrm{O}$ livro do próprio Späth (SPÄTH 1994), com foco na construção da masculinidade em Tácito, faz o mesmo, aplicando os métodos dos estudos de gênero para o campo da história antiga, antes de gênero se tornar uma disciplina central. O último livro, "Im Zeichen des Phallus", tese de doutorado de Eckhard Meyer-Zwiffelhoffer (MEYERZWIFFELHOFFER 1995), também trata de gênero. Sua abordagem é claramente inspirada por Michel Foucault e é um estudo pioneiro do discurso sexual romano. Cada um dos livros discutidos por Späth lida menos com acontecimentos históricos ou estruturas sociais do que com os diferentes aspectos da cultura.

\footnotetext{
${ }^{1}$ Devo muito ao Prof. Dr. Fábio Faversani e ao Prof. Dr. Fábio Joly por sua ajuda com a publicação deste artigo e ao Dr. John N. Dillon pela revisão do texto em Inglês. Desnecessário dizer que todos os erros remanescentes são de minha responsabilidade.

${ }^{2}$ As comunidades científicas da Áustria e Suíça estão estreitamente conectadas com a alemã. Doravante, por brevidade, "Alemanha" será usada pars pro toto para o conjunto dos três países.

${ }^{3}$ Se sua análise do medo senatorial é bem sucedida é outra questão; cf. a resenha crítica de Winterling (2000).
} 
O que Späth chama de "nova história" pode, assim, ser visto como história cultural. E esta nova história cultural da década de 1990 não se limitou à história antiga, mas foi parte de uma mudança maior na historiografia alemã como um todo - uma mudança que, por vezes, é rotulada de "giro cultural". ${ }^{4}$

Falar em "giros" é sempre difícil. ${ }^{5}$ Se fossemos esboçar os contornos simplificados do progresso da nova história cultural, ${ }^{6}$ apontaríamos que na Alemanha ela apareceu primeiro nos anos 1990 (com vários precursores nos anos 1980) e se coloca em oposição à "Sozialgeschichte" ou história social. A "Sozialgeschichte" alemã foi dominante principalmente nos anos 1970 e se concentrava nos "fatos" sociais duros em amplas estruturas macrohistóricas. Historiadores como Hans Ulrich Wehler ou, na história antiga, o falecido Géza Alföldy com seu influente "Römische Sozialgeschichte", foram destacados representantes dessa linha de pensamento (ALFÖLDY 2011). ${ }^{7} \mathrm{O}$ "giro cultural" da década de 1990 não tinha uma fonte, nem foi limitado à Alemanha. ${ }^{8}$ A "microstoria" italiana, com seu foco em pequenas unidades e nos diferentes aspectos da vida cotidiana antes do que em amplas unidades, em superestruturas sociais merece uma menção especial. ${ }^{9}$ Mas não apenas na Itália, na Alemanha também, historiadores, primeiro uma maioria da era moderna, passaram a se interessar pela história local e pela vida cotidiana. O foco transferiu-se das macroestruturas objetivas para o modo como as pessoas percebiam estas estruturas em um nível subjetivo na vida cotidiana. ${ }^{10}$ Outra tendência foi o aumento no interesse dos historiadores alemães quanto aos métodos e teorias da antropologia cultural, o que levou à nova disciplina da antropologia histórica (Cf. WINTERLING 2006). ${ }^{11}$ Aqui, o historiador da Antiguidade Jochen Martin é uma figura proeminente. ${ }^{12}$ Certamente não é coincidência que os quatro livros discutidos por Thomas Späth como constituindo uma "nova história antiga" estavam todos - de uma maneira ou de outra - ligados a Jochen Martin. Uma terceira tendência foi o crescente interesse na história feminista e, especialmente, na construção dos papéis de gênero. Isso levou os historiadores a refletir sobre como o gênero, a sexualidade e o corpo humano são percebidos em diferentes épocas e em diferentes culturas. Todas essas tendências podem ser agrupadas sob o rótulo de "história cultural".

\footnotetext{
${ }^{4}$ Uma breve síntese sobre este"giro" e o desenvolvimento de uma "nova história cultural" na Alemanha pode ser encontrada em TSCHOPP; WEBER 2007, p. 72-82.

5 Para uma discussão inteligente sobre diferentes "giros culturais", ver BACHMANN-MEDICK 2006, que toma os "giros" não tanto como um foco voltado a novos objetos mas sobretudo como um foco voltado a novas categorias analíticas.

6 O rótulo "nova" é usado para colocar esta história cultural em separado da"velha" história cultural do século XIX. 7 WEHLER 1998 apresenta uma discussão sobre a mudança (e as oportunidades) que a história cultural representa com relação à "Sozialgeschichte".

${ }^{8}$ A bibliografia é vasta. Para uma visão panorâmica recente, ver HUMM 2010; monografias mais recentes e manuais incluem: DANIEL 2006; ORY 2007; TSCHOPP; WEBER 2007; TSCHOPP 2008. Para um foco especialmente voltado para a história antiga, ver SCHMITZ 2010.

9 Para o trabalho de Carlo Ginzburg no contexto do desenvolvimento da história cultural, ver DANIEL 2006, p. 285-296.

10 Para a história alemã da vida cotidiana, ver LÜDTKE 1989, e para o contexto mais amplo, ver DANIEL 2006, p. 298-313.

${ }_{11}$ Discussões teóricas da história cultural e antropologia histórica podem ser encontradas na revista "Historische Anthropologie", que começou a ser publicada em 1993. Para um panorama recente, escrito por ocasião do vigésimo aniversário do periódico, ver BURSCHEL 2012.

12 Martin influenciou o campo não somente através de suas publicações (as mais importantes das quais estão coligidas em MARTIN 2009), mas também institucionalizando a antropologia histórica como uma disciplina na Universidade de Freiburg.
} 
O foco delas não recai mais sobre os "fatos duros" da sociedade (i.e., a descrição de suas instituições ou de suas estruturas políticas e econômicas), mas em sua cultura - "cultura" sendo entendida como a totalidade das representações, práticas e símbolos por meio dos quais os seres humanos percebem e sentem o mundo. Esta abordagem descortina toda uma nova série de problemas, como ilustrado pelos quatro exemplos de Spath: ao invés de estudar acontecimentos políticos ou estruturas sociais, Egon Flaig pesquisou rituais e símbolos que, na prática política, poderiam desenvolver um poder próprio; Dirk Barghop buscou encontrar uma forma objetiva para descrever o sentimento subjetivo de medo no senado romano; Meyer-Zwiffelhoffer analisou o discurso sexual da antiga Roma, e Thomas Späth investigou como os Romanos conceberam e construíram papéis de gênero. A amplitude dos temas agrupados sob o rótulo de "história cultural" dá legitimidade aos estudiosos que defendem que o "giro cultural" em curso está afetando a história como um todo.

Há duas objeções principais a fazer história desta maneira. A primeira é que a cultura como uma categoria que descreve todos os tipos de representações e práticas humanas pode ser aplicada a virtualmente qualquer coisa, fazendo a história cultural uma disciplina indefinível. Isto é verdade em certa medida. Frequentemente, a história cultural é usada como uma subcategoria histórica entre muitas, mesmo que não esteja realmente claro como a história cultural difere, digamos, da "antropologia histórica", da "história do corpo" ou da "história de gênero". O erudito francês Pascal Ory tentou definir a história cultural como 134 história dos símbolos, práticas e representações. A história cultural deveria ser vista, argumenta Ory, como um dos três principais enfoques da história - os outros dois sendo as histórias política e econômica (ORY 2007, p. 21s.). Deste ponto de vista, a "antropologia histórica", a "história de gênero", e assim por diante, nada mais seriam do que subcategorias da "história cultural". Mas se tomarmos seriamente a inferência de que cultura inclui todas as representações humanas e pode ser usada para descrever todos os modos pelos quais os homens dão sentido ao mundo que os cerca, então a história cultural não pode ser vista meramente como uma subcategoria da história, nem mesmo como uma amplíssima subcategoria, mas deve ser vista como uma nova maneira de fazer história. Ory está bem consciente disto ${ }^{13}$. Assim, em seu modo de ver, a história política e econômica são enfoques diferentes para a história, mas não assuntos diferentes. Assim, há também uma história cultural da política, sem a qual poder-se-ia alegar acertadamente que a história política não poderia ser compreendida; e historiadores da Antiguidade em particular notaram há muito que a história econômica deve ser vista em parte ao menos como incorporada na sociedade: deste modo, também é, em larga medida, história cultural. Neste sentido, história cultural não é um tema especial ou método específico, mas ao contrário é uma categoria analítica aplicável a todos os campos da história.

13 Ver ORY 2007, p. 7-28 para uma discussão completa sobre os problemas das definições. Que a história cultural não pode ser vista como uma simples subcategoria da história é também a abordagem adotada por DANIEL 2006, p. 7-25 em sua introdução, "Kulturgeschichte - und was sie nicht ist" ("história cultural - e o que ela não é"). 
Ainda permanece, contudo, a segunda objeção levantada contra a história cultural. Esta objeção diz respeito aos métodos aplicados na história cultural: o fato de que a história cultural é um novo enfoque não significa que ela é um novo método. Assim, estudiosos que fazem história cultural muitas vezes adotam uma abordagem interdisciplinar, emprestando teorias de antropólogos, de sociólogos, dentre outros. ${ }^{14}$ Esta abertura, combinada com a já ainda mais aberta definição do que é "cultura", ameaça tornar a história cultural em uma espécie de "território onde vale tudo", onde estudiosos podem utilizar as teorias que prefiram indistintamente a todo tipo de banalidades. Para enunciar esta objeção de uma maneira polêmica, história cultural, no sentido mais negativo, seria o exato oposto de "história social", na medida em que ela foca somente nas representações, textos e símbolos e ignora completamente os dados históricos; ela se orna com teorias fortuitas de outras disciplinas, mas carece de um método histórico rigoroso. Assim, em certo sentido, "história cultural" pode ser usada como rótulo para descrever uma maneira moderna, atualizada de se fazer história, mas pode ser usada também polemicamente para denunciar uma especulação sofisticada que faz uso de teorias fortuitas de outras disciplinas e carece de uma base histórica acabada. Em alguns casos, esta crítica pode ser justificada, mas ela é devida a uma falha de estudos individuais e não à história cultural como um todo. Estudar a cultura entendida como o conjunto de representações feitas pelo homem não implica alijamento dos métodos históricos tradicionais e limitar-se apenas à especulação sofisticada. História cultural deve, ao contrário, ser vista como um convite a usar novas teorias e modelos, em conjunto com os métodos tradicionais, a fim de considerar problemas antigos desde novas perspectivas.

História cultural é um fenômeno antes global do que alemão. "Kulturgeschichte" pode ter sido praticada na Alemanha no século XIX e "clássicos" como Jacob Burckhardt ainda se mostram como uma fonte de inspiração, mas as influências que conduziram ao "giro cultural" nos anos 1980 e 1990 não podem ser vistas como uma tradição contínua que remonta ao século XIX, nem foram elas todas domésticas (Cf. HUMM 2010, p. 10ss). ${ }^{15}$ A academia alemã deve ser vista como parte de uma comunidade global que não se limita a um discurso nacional, mas, antes, incorpora várias influências de origens diversas. A recepção de filósofos pós-estruturalistas como Michel Foucault ou Pierre Bourdieu cumpriu um papel importante, e a antropologia cultural como é exercida no mundo anglófono também foi muito influente. Outra fonte fundamental é a história feminista e os estudos de gênero, que não podem ser reduzidos a um único discurso nacional. Assim, de muitas maneiras, a "história cultural" na Alemanha hoje não é muito diferente de suas congêneres no mundo anglófono ou francófono. Mas há certos traços nacionais que influenciam o modo pelo qual a história cultural é vista na Alemanha. Por um lado, as tradições nacionais determinam o tipo de história com relação a

${ }^{14}$ A interdisciplinariedade da história cultural é o principal foco de SCHMITZ 2012.

15 Para um panorama que leva em conta as tradições do século XIX, ver TSCHOPP 2008a. 
qual a história cultural se contrapõe. Na Alemanha, foi claramente em oposição à história social como esboçamos acima e - especialmente na história antiga uma contraposição à história política e constitucional. ${ }^{16}$ Quando nos dirigimos à França, podemos observar que esta oposição não é tão proeminente como do outro lado do Reno: a influente escola dos Annales tinha se afastado da história política havia tempo e teve interesse em temas como os da história das mentalidades muito precocemente. A história cultural como uma história das representações não era de fato algo tão novo na França e podia ser tomada como uma continuação das tradições francesas. Deste modo, o historiador da Antiguidade francês Michel Humm afirmou em um artigo recente que a história cultural feita na Alemanha desde os anos 1990 é de fato uma "histoire culturelle à la française" (HUMM 2012, p. 11). Assim, ainda que a história cultural na França e na Alemanha não seja muito diferente hoje, cada versão emerge de tradições diferentes. Estas tradições nacionais - e este é meu segundo problema - não somente determinam o modo como a história cultural é percebida, ou seja, se como algo novo, estrangeiro ou tradicional; tradições nacionais também, em certa medida, determinam que temas são analisados com os métodos da história cultural. Provavelmente não é coincidência que muitos estudos de historiadores da Antiguidade na Alemanha ao longo de vários dos últimos anos se centraram na cultura política da Roma Antiga, sendo construídos com base nos trabalhos clássicos da academia alemã, como aqueles de Christian Meier, Matthias Gelzer ou Theodor Mommsen, e vendo estes trabalhos sob uma nova luz. Egon Flaig (2003), Karl-Joachim Hölkeskamp (2004) e Martin Jehne (1995), em particular, estudaram os rituais e símbolos que tiveram um papel na cultura política da República Romana. Em parte como uma reação a Fergus Millar, estes estudos procuram mostrar que, ainda que muitas instituições republicanas eram "democráticas", a cultura que fez estas instituições funcionarem era completamente aristocrática. Outros estudos se concentram na vida cotidiana e interação ritual dos aristocratas. Muitos estudos surgiram nos últimos dez anos que investigam o convivium, incluindo aqueles de Elke Stein-Hölkeskamp (2005), Konrad Vössing (2008) e recentemente Dirk Schnurbusch (2011). Os trabalhos de Aloys Winterling e Fabian Goldbeck sobre amizade, patronato e a instituição da salutatio adotam uma abordagem similar: enquanto os estudos anteriores davam atenção ao patronato como uma explicação relativamente mecânica sobre como os romanos operavam, Winterling e Goldbeck se concentraram no valor simbólico da amizade (WINTERLING 2008 [= WINTERLING 2009]; GOLDBECK 2010; MEISTER 2013). ${ }^{17}$ Ter muitos "amigos" acorrendo a sua salutatio, assim propõe a tese, não é tanto um instrumento de alavancagem política, sendo mais

\footnotetext{
${ }_{16}$ A situação na história antiga é assim ligeiramente distinta daquela de outras épocas, quando a história social nos anos 1960 e 1970 era tomada como o novo paradigma, oposto às velhas formas da história política e constitucional. Uma distinção clara como esta não pode ser delineada na história antiga, onde a história constitucional sempre foi história social em certa medida e vice-versa. Isto também significa, contudo, que a história política e constitucional manteve áreas com relação às quais as novas abordagens histórico-culturais tentaram se afastar. Assim, o modelo de Flaig de Principado Romano como um "Akzeptanzsystem" (sistema de aceitação) é apresentado como uma nova abordagem opondo-se à visão constitucional que remonta ao "Staatsrecht" de Mommsen; ver FLAIG 1992, p. 174-207.

17 NIPPEL 2002 oferece um panorama da pesquisa sobre a amizade e clientela romanas.
} 
uma manifestação de prestígio, que pode ser entendida apenas no contexto da cultura aristocrática romana. Assim, patronato e amizade - temas fundamentais na academia alemã desde Gelzer - são vistos sob uma nova luz.

Um caso especial no amplo campo da história cultural é a história do corpo. ${ }^{18}$ A história do corpo exemplifica todas as vantagens e desvantagens da história cultural. Antes de tudo, uma questão deve ser colocada: como o corpo humano pode ter uma história? Aqui, uma vez mais, podemos ver como abordagens nacionais e disciplinares descortinaram esse novo campo da história. Uma linha importante de pensamento deriva da antropologia. Já nos anos 1930, o antropólogo social francês Marcel Mauss publicou um artigo sobre "técnicas do corpo" (MAUSS 1936), no qual ele defendia que muitas coisas que acreditamos serem naturais sobre o corpo são, na verdade, moldadas pela cultura. Fazendo uso de uma quantidade imensa de dados coletados durante toda uma vida de estudos, ele pode mostrar que os modos como as pessoas andam, sentam, comem ou dormem diferem significativamente em diferentes sociedades e devem ser vistos como produtos não da natureza, mas da sociedade. Mais de trinta anos depois, a antropóloga inglesa Mary Douglas tomou esta ideia e a aprofundou (DOUGLAS 1973, p. 69-87), assim como fez o sociólogo francês Pierre Bourdieu, ${ }^{19}$ que começou sua carreira não como sociólogo, mas, como Douglas e Mauss, como antropólogo. Antropólogos e sociólogos começaram a dedicar sua atenção ao modo como os corpos são percebidos e condicionados, ao modo como se movem e se vestem e ao modo como sociedades lidam com atrativos e deformidades corporais. Obviamente, historiadores podem fazer exatamente as mesmas perguntas.

Antropologia e sociologia têm uma influência fundamental sobre a história do corpo. Mas, na minha opinião, os estudos de gênero e a história da sexualidade foram mais influentes. O livro inovador de Kenneth Dover sobre a homossexualidade grega demonstrou, no final dos anos 1970, que os antigos gregos não tinham de fato um conceito de "homossexualidade", mas antes pensaram sexualidade em termos de papéis ativos e passivos (DOVER 1978). Estes resultados foram aceitos por Michel Foucault no segundo volume de sua Histoire de la sexualité, onde Foucault usou a Grécia antiga para demonstrar que as práticas sexuais não eram algo natural, mas sim moldadas pelo discurso (FOUCAULT 1984)..$^{20}$ O aparecimento do livro de Foucault levou a uma verdadeira enxurrada de publicações sobre sexualidades antigas, identidades sexuais e modos de conceber e elaborar corpos sexualizados no mundo antigo. ${ }^{21}$ O crescente interesse em estudos de gênero, a autoridade de Foucault e o fato de que as práticas sexuais antigas eram muito diferentes das modernas fez da sexualidade antiga um campo fundamental de interesse acadêmico em

\footnotetext{
${ }_{18}$ Para uma introdução geral, ver LORENZ 2000.

19 Para os conceitos de "Habitus" e "Hexis" em Bourdieu, ver (entre outros) BOURDIEU 1993, p. 97-156 e BOURDIEU; WACQUANT 2006, p. 157-175; para uma visão geral, cf. KRAIS; GEBAUER 2008.

20 Para Roma: FOUCAULT 1984a.

21 MEYER-ZWIFFELHOFFER 1995 deveria ser visto neste contexto; cf. para os anos 1990 (entre muitos outros): HALPERIN; WINKLER; ZEITLIN 1990; GLEASON 1995; HALLETT; SKINNER 1997; WYKE 1998; WILLIAMS 1999. Os ideais de castidade e abstinência sexual e a influência destes conceitos para o corpo na Antiguidade Tardia são trabalhados por BROWN 1988.
} 
todo o mundo. Assim, embora a sexualidade seja apenas um aspecto do corpo humano - e não necessariamente o mais importante -, este tem sido o foco principal da história do corpo na história antiga pelos últimos vinte anos. Outros aspectos, como a história da medicina, a estranha ciência antiga da fisiognomia ou as várias metáforas corporais utilizadas na linguagem antiga, embora não completamente ignorados, nunca alcançaram a mesma popularidade que teve o estudo do corpo sexualizado. ${ }^{22}$ Ao longo dos últimos anos, no entanto, o foco se ampliou: Philip van der Eijk - "Alexander von Humboldt professor" na Universidade Humboldt, Berlim - está trabalhando atualmente em um grande projeto dedicado à história da medicina e à conceituação do corpo humano na ciência e filosofia antigas ${ }^{23}$. Há alguns anos atrás, Simon Swain editou um extenso volume sobre o antigo sofista Polemão e a peculiar arte da fisiognomia (SWAIN 2007). Um estimulante livro de 2004 de Anthony Corbeill investigou a "natureza incorporada" na Roma antiga, e dois anos depois Matthew Roller (2006) publicou um importante estudo sobre as posturas nas refeições romanas. Outros aspectos também, como o "corpo vestido", começaram a atrair. a atenção dos estudiosos (CLELAND; HARLOW; LLEWELLYN-JONES 2005) ${ }^{24}$ Na França, a história do corpo tornou-se um tema fundamental ao longo dos últimos dez anos, e vários volumes dedicados ao assunto foram publicados. ${ }^{25}$ Estudiosos franceses foram atraídos principalmente para fisiognomia e gênero, mas muitos outros assuntos também têm recebido atenção, indo desde a interação entre os corpos até o valor simbólico de cicatrizes, a importância do cabelo ou a relação iconográfica do corpo com a armadura na pintura dos vasos áticos. O crescente interesse dos estudiosos franceses pode ser percebido pelo fato de que a "Journée de printemps de la SOPHAU" de 2013 foi dedicada exclusivamente à história do corpo e procurou dar uma visão geral da rica erudição produzida neste campo. ${ }^{26}$ A publicação recente editada por Daniel H. Garrison (2010) oferece uma boa mostra da ampla gama de temas e abordagens que a história do corpo incorpora hoje: o corpo sexualizado é tratado juntamente com as questões do nascimento e da morte, temas da saúde, corpos divinos e a inter-relação entre o corpo e a própria pessoa. Como o título do livro indica, oferece uma "história cultural do corpo humano", que exemplifica a diversidade e o potencial do assunto.

Recapitulando: a história do corpo, de forma análoga à história cultural, em termos gerais, não pode ser reduzida a um discurso nacional ou a uma disciplina isolada. Sociologia, antropologia e estudos de gênero, todos tiveram um papel na formação do modo como o campo é estudado hoje. Mas há outro aspecto que

\footnotetext{
22 Medicina e fisiognomia foram explorados por BARTON 1994 e VOGT 1999; metáforas corpóreas são trabalhadas por GULDIN 2000; corpos com necessidades especiais são o tema de GARLAND 1995; uma ampla mirada sobre o corpo é dada por PORTER 1999.

23 Para uma descrição do projeto "Medicina da mente, filosofia do corpo. Discursos de saúde e bem-estar no mundo antigo", ver http://www.klassphil.hu-berlin.de/avh-professur (acessado em 18/01/2013).

24 É claro, todos estudos com ênfase nas vestimentas estão relacionados com o corpo de uma maneira ou de outra. Estudos recentes incluem EDMONDSON; KEITH 2008; STARBATTY 2010; GHERCHANOC; HUET 2012. 25 Três volumes foram publicados na série "Cahiers d'histoire du corps antique" até aqui: PROST; WILGAUX 2006; BODIOU; FRÈRE; MEHL 2006; DASEN; WILGAUX 2008; para os estudos acadêmicos sobre a história do corpo, ver também MOREAU 2002; GARELLI; VISA-ONDARÇUHU 2010.

${ }^{26}$ Os anais da conferência estão para ser publicados em um suplemento de Dialogues de l'Histoire Ancienne; para a programação, ver: http://sophau.univ-fcomte.fr (acessado em 27/06/2013).
} 
a história do corpo tem em comum com a história cultural: assim como "cultura" é difícil de definir, assim também é o "corpo". A maioria das pessoas pensa que sabe o que o corpo é, mas dificilmente você vai encontrar duas pessoas que concordem sobre os detalhes. Longas discussões são possíveis sobre se o cabelo é realmente parte do corpo, se o corpo pode ser percebido separadamente da roupa ou se devemos, antes, falar de corpo vestido, e se o que Mauss denominou de técnicas corporais não deveriam ser vistas, antes, como comunicação ou interação. Estas são questões que não podem ser respondidas correta ou incorretamente; as respostas dependem da perspectiva que se escolha. Tais questões, no entanto, colocam em evidência um grande problema com a história do corpo. Carolyn Bynum escreveu certa feita que "o corpo" não é realmente um assunto independente: ${ }^{27}$ ou o corpo é uma questão biológica, caso em que ele não tem história, ou ele é formado e percebido, ou mesmo completamente construído, pela cultura, caso em que é impossível traçar uma fronteira clara na qual a história do corpo termina e a história cultural começa. Quando estudiosos como Judith Butler (1993) argumentam que o corpo é construído inteiramente através da atuação e do discurso, o corpo se torna um ato voluntário que pode ser quase qualquer coisa. Bynum propôs apreender o corpo como ligado a três questões fundamentais: identidade, desejo e materialidade. As perguntas sobre como corpos e identidades estão inter-relacionados, como o desejo é concebido apenas em conexão com o corpo e a forma como lidamos com a materialidade do corpo, especialmente quando os corpos envelhecem ou morrem, parecem fundamentais para a nossa percepção de corpos (BYNUM 1996, p. 8ss.). ${ }^{28}$ Em uma criativa leitura enviesada de Bynum, pode-se usar estas três categorias como uma definição frouxa do que estudamos quando pesquisamos a história do corpo. Esta é uma definição de trabalho com a qual eu, pessoalmente, concordaria, embora ela não possa realmente nos ajudar a responder a perguntas como se o cabelo deve ser entendido como parte do corpo ou não. Assim, o corpo visto como parte integrante da cultura com enfoque nestes três aspectos - desejo, materialidade e identidade - é muito mais do que a soma das partes do corpo - e traz à luz perspectivas muito mais amplas. Isso também implica, no entanto, que a história do corpo não é algo exótico, diferente de outros temas da história, mas transpassa campos tradicionais de pesquisa em muitos pontos. Centrando-se no corpo e através da aplicação de teorias sociológicas ou antropológicas, temos uma melhor compreensão não só da história do corpo humano, mas também - e talvez ainda mais importante - das sociedades passadas que moldaram esses corpos históricos e suas representações.

Assim como a história cultural, a história do corpo não é um fenômeno alemão e não pode ser entendida considerando a academia alemã isoladamente. Com este senão, gostaria de apontar alguns dos principais trabalhos neste campo que têm aparecido na Alemanha nas últimas décadas. Em primeiro lugar, temos o já mencionado estudo de Eckhard Meyer-Zwiffelhoffer (1995).

\footnotetext{
27 BYNUM 1996; para a citação, p. 1.

${ }^{28}$ O quanto seja possível a percepção do corpo como não sendo composta pelo discurso é o assunto de SARASIN 1999.
} 
Este é um livro que analisa os discursos que moldaram as práticas sexuais romanas. É, portanto, um estudo que se coloca na tradição de Foucault. Embora o corpo não seja seu foco central, deve-se notar que Meyer-Zwiffelhoffer mostra como a sociedade romana lida com os desejos corporais - ele está, portanto, preocupado com um dos três aspectos principais aos quais Bynum atribui centralidade para a percepção do corpo. Um segundo estudo que merece ser mencionado aqui é um pequeno livro publicado por Lukas Thommen em 2007. Continua sendo ainda hoje o único manual que abrange todo o campo da história do corpo na Antiguidade grega e romana. Thommen considera muitos aspectos diversos, tais como o discurso médico, o ideal grego de kalokagathia, o treino do corpo, gênero e sexualidade, corpos cristãos - só para citar alguns. Sua monografia segue sendo, no entanto, um manual de menos de 150 páginas e o tratamento é necessariamente breve. Para além deste amplo panorama, vários estudos especializados surgiram. Em 2010, foi publicado um volume editado na Áustria unindo vários estudos de caso com foco principalmente no atletismo antigo e no ideal de kalokagathia (MAURITSCH 2010). Surgiram duas publicações recentes de Edith Hummer (2006) e Henning Wirth (2010), ambas visando os canhotos na Antiguidade - um assunto que anteriormente nunca tinha sido tratado em uma monografia. No entanto, especialmente o estudo de Wirth - ainda que não neguemos seus méritos - mostra que a história do corpo não precisa, necessariamente, ser feita como história cultural: muitas das abordagens de Wirth são bastante positivistas, reunindo os fatos conhecidos e fazendo perguntas como se César era canhoto ou não. ${ }^{29}$

Uma abordagem totalmente diferente, baseada na cultura, é adotada por Dirk Barghop (1994), cujo livro foi mencionado acima. Ainda que seu objetivo principal seja estudar o medo senatorial, o corpo humano é fundamental para a sua abordagem teórica. Aplicando as teorias de Pierre Bourdieu para os senadores romanos, Barghop tenta analisar o modo como senadores se moviam, falavam e agiam como um "habitus" classista. Através desse habitus, senadores romanos se apresentavam e atuavam como corporificações da república e, assim, traziam a república e suas instituições à vida. $O$ aparecimento de um imperador, assim segue o argumento, era incompatível com este habitus e por isso levou ao medo senatorial. Embora eu não concorde muito com esta conclusão, avalio a ideia de aplicar as teorias de Bourdieu a Roma e ver o senado como uma corporificação da velha república como muito atraentes. ${ }^{30}$

Este foi o ponto de partida para o meu próprio estudo sobre o corpo do imperador romano (MEISTER 2012). A minha principal questão era como um monarca se apresenta em uma sociedade que nega ser uma monarquia e finge ser uma república. Se dermos uma olhada em monarquias em outras culturas, descobrimos que ser um monarca tem muito a ver com as aparências: um rei deve atuar como o símbolo da terra e das pessoas que ele governa, ele é cercado por pompa real, roupas especiais e cerimônias o marcam como um

\footnotetext{
${ }^{29}$ Cf. minha resenha do livro de Wirth em MEISTER 2011.

30 Para aplicações das teorias de Bourdieu aos senadores romanos, ver CORBEILL 2002 (= CORBEILL 2004, p. 107-139); MEISTER 2009
} 
corpo especial distinto de seus súditos. Ernst Kantorowicz (1957), em seu famoso estudo sobre a Europa medieval e o início da era moderna, apontou que os reis europeus eram percebidos como tendo dois corpos: um "corpo natural", que envelhece e morre, e um "corpo político", que é a encarnação imortal da posição real. A Inglaterra dos Tudor desenvolveu uma teoria complicada destes dois órgãos que são separados e ainda assim inseparáveis - uma teoria que, em muitos aspectos, se assemelha às duas naturezas de Cristo. Não tenho espaço aqui para entrar em detalhes. A questão importante é que tal teoria não teria funcionado na Roma antiga. Autores romanos podem pensar a República com metáforas corporais, mas o corpus rei publicae é algo que existia antes do aparecimento de um monarca, e a relação entre este corpus rei publicae e o corpus principis é problemática de um modo que seria impensável na Europa medieval tardia (MEISTER 2012, p. 153-192). O mesmo vale para a forma como o imperador romano figurava entre seus pares. Distinto de um monarca real, ele não poderia se distinguir por roupas especiais ou cerimônias reais, antes tinha que representar um papel e atuar como se Roma ainda fosse uma república ao invés de se apresentar como a incorporação da nova monarquia, o que teria sido o curso natural dos eventos. Pelo contrário, o imperador tinha que evitar a todo custo que a monarquia se tornasse visível. Embora o imperador tivesse um poder quase absoluto, na interação cotidiana com seus colegas senadores ele tinha que manter a ilusão de que a república e suas instituições ainda estavam vivas (MEISTER 2012, p 109-131; 222-255).

Se tomarmos as teorias de Bourdieu e sua aplicação para o Senado romano a sério, então tal ato deliberado por parte do imperador estava condenado ao fracasso. Bourdieu define "habitus" como algo concebido como verdadeiro: senadores romanos são senadores romanos, pois eles atuam como senadores romanos, porque andam, falam e vestem-se como senadores. O imperador, contudo, não é um senador: mesmo que atue como um senador, se movimente e fale como um senador e use uma toga senatorial, ele é, ainda assim, diferente. Sua aparência é, portanto, insincera e seu corpo já não mostra o que ele realmente é; é concebido como um corpo enganoso colocado à parte de si mesmo. Se lembrarmos dos três aspectos que Carolyn Bynum considera centrais para a percepção humana do corpo - materialidade, desejo e identidade - podemos ver que no Alto Império a conexão entre o corpo e a identidade do imperador era bastante problemática. Esse problema deixou marcas em muitas fontes diferentes e lança uma nova luz sobre antigos problemas relativos ao estabelecimento da monarquia na Roma republicana. ${ }^{31}$

Só porque o meu livro é a mais recente publicação sobre a história do corpo na Alemanha não significa que esse é o fim desta. Há muitos tesouros esperando para serem descobertos ou, mais precisamente, muitos tesouros que foram descobertos e ainda estão à espera de publicação. Duas "Qualifikationsschriften" com foco na história do corpo foram premiadas nos últimos anos, mas ainda não

\footnotetext{
${ }^{31}$ Cf. MEISTER 2012, p. 131-153 para a literatura romana em geral; 192-222 para as estátuas; 249-255 para a visão de Tácito sobre a falta de sinceridade do imperador e 255-270 para a redefinição de Suetônio dos corpos indefinidos dos imperadores.
} 
foram publicadas. A primeira é a "Habilitationsschrift" de Adrian Stähli (2002) apresentada na Universidade de Zurique em 2002 e premiada com o "UBS Habilitationspreis" em 2003. Stähli é um arqueólogo clássico e atualmente "Loeb Professor" em Harvard. ${ }^{32}$ Seu estudo se concentra na nudez na Grécia antiga, na sua percepção na cultura europeia e na questão do que isto pode nos ensinar sobre as estéticas - antigas e modernas - envolvidas. Certamente será de grande valor para a pesquisa futura. O segundo estudo é a "Habilitationsschrift" de Johanna Fabricius (2003) apresentada à Universidade de Göttingen, em 2003, e que recebeu o prêmio Bruno-Snell em 2005. Como Stähli, Fabricius é arqueóloga clássica e atualmente "professor" na Universidade Livre, Berlim. Seu trabalho apresenta uma comparação de como os corpos humanos foram concebidos na Grécia e em Roma e adota uma abordagem abrangente, que leva em conta não só as representações iconográficas, mas também os aspectos linguísticos e literários. Seu estudo muito provavelmente será, portanto, de grande interesse não só para os arqueólogos, mas também para os historiadores da Antiguidade e filólogos clássicos. Para avançar uma conclusão, então, a história do corpo dentro do contexto da história cultural talvez não seja o foco central da academia alemã, mas, apesar disso, esta tem conduzido vários novos estudos ao longo dos últimos anos e esperamos que continue a fazê-lo no futuro.

\section{Referências bibliográficas}

ALFÖLDY, Géza. Römische Sozialgeschichte. Stuttgart, 2011 (4th ed.) [The Social History of Rome. London, 1985].

BACHMANN-MEDICK, Doris. Cultural Turns. Neuorientierungen in den Kulturwissenschaften. Hamburg, 2006.

BARGHOP, Dirk. Forum der Angst. Eine historisch-anthropologische Studie zu Verhaltensmustern von Senatoren im römischen Kaiserreich. Frankfurt, 1994.

BARTON, Tamsyn S. Power and Knowledge. Astrology, Physiognomics, and Medicine under the Roman Empire. Ann Arbor, 1994.

BODIOU, Lydie, FRÈRE, Dominique; MEHL, Veronique (eds.). L'expression des corps. Gestes, attitudes, regards dans l'iconographie antique. Rennes, 2006.

BOURDIEU, Pierre. Sozialer Sinn. Kritik der theoretischen Vernunft. Frankfurt, 1993 [Le sens pratique. Paris, 1980].

; WACQUANT, Loïc J. D. Reflexive Anthropologie. Frankfurt, 2006 [Réponses pour une anthropologie réflexive. Paris, 1992].

BROWN, Peter. The Body and Society. Men, Women and Sexual Renunciation in Early Christianity. New York, 1988.

\footnotetext{
32 "Professor" no sistema universitário britânico e estadunidense é um título reservado a acadêmicos nas mais elevadas posições acadêmicas, diversamente do que ocorre no sistema brasileiro em que todos os que ministram aulas são tratados de professor.
} 
BURSCHEL, Peter. Wie Menschen möglich sind. 20 Jahrgänge "Historische Anthropologie". Historische Anthropologie 20, 2012, p. 152-161.

BUTLER, Judith. Bodies that Matter. New York, 1993.

BYNUM, Caroline. Warum das ganze Theater mit dem Körper? Die Sicht einer Mediävistin. Historische Anthropologie 4, 1996, p. 1-33.

CLELAND, Liza; HARLOW, Mary; LLEWELLYN-JONES, Lloyd (eds.). The Clothed Body in the Ancient World. Oxford, 2005.

CORBEILL, Anthony. Political Movement. Walking and Ideology in Republican Rome. In: FREDRICK, David (ed.), The Roman Gaze. Vision, Power, and the Body. London, 2002, p. 182-215.

. Nature Embodied. Gesture in Ancient Rome. Princeton (N. J.), 2004.

DANIEL, Ute. Kompendium Kulturgeschichte. Theorien, Praxis, Schlüsselwörter. 5th ed. Frankfurt, 2006.

DASEN, Véronique; WILGAUX, Jérôme (eds.). Langages et métaphores du corps dans le monde antique. Rennes, 2008.

DOUGLAS, Mary. Natural Symbols. Explorations in Cosmology. 2nd ed. London, 1973.

DOVER, Kenneth J. Greek Homosexuality. London, 1978.

EDMONDSON, Jonathan; KEITH, Alison (eds.). Roman Dress and the Fabrics of Roman Culture. Toronto, Buffalo and London, 2008.

FABRICIUS, Johanna. Soma/corpus. Körperbild und Körperkonzepte in der griechischen und römischen Kultur. Habil. Göttingen, 2003 (unpublished) [non vidi].

. Natürlich oder konstruiert? Körper und Sprache in Griechenland und Rom. Raumwissen 2, 2010, p. 18-21.

FLAIG, Egon. Den Kaiser herausfordern. Die Usurpation im römischen Reich. Frankfurt, 1992.

Ritualisierte Politik. Zeichen, Gesten und Herrschaft im Alten Rom. Göttingen, 2003.

FOUCAULT, Michel. Histoire de la sexualité. Vol. 2: L'usage des plaisirs. Paris, 1984.

Histoire de la sexualité. Vol. 3: Le souci de soi. Paris, 1984a.

GARELLI, Marie-Hélène; VISA-ONDARÇUHU, Valérie (eds.). Corps en jeu. De I'Antiquité à nos jours. Rennes, 2010.

GARLAND, Robert. The Eye of the Beholder. Deformity and Disability in the Graeco-Roman World. 2nd ed. 2010. London, 1995.

GARRISON, Daniel H. (ed.). A Cultural History of the Body in Antiquity. Oxford and New York, 2010. 
GHERCHANOC, Florence; HUET, Valérie (eds.). Vêtements antiques. S'habiller, se déshabiller dans les mondes anciens. Arles, 2012.

GLEASON, Maud W. Making Men. Sophists and Self-Presentation in Ancient Rome. Princeton (N. J.), 1995.

GOLDBECK, Fabian. Salutationes. Die Morgenbegrüßungen in Rom in der Republik und der frühen Kaiserzeit. Berlin, 2010.

GULDIN, Rainer. Körpermetaphern. Zum Verhältnis von Politik und Medizin. Würzburg, 2000.

HALLETT, Judith P.; SKINNER, Marilyn B. (eds.), Roman Sexualities. Princeton, (N. J.) 1997.

HALPERIN, David M.; WINKLER, John J.; ZEITLIN, Forma I. (eds.). Before Sexuality. The Construction of Erotic Experience in the Ancient Greek World. Princeton (N. J.), 1990.

HÖLKESKAMP, Karl-Joachim. Rekonstruktionen einer Republik. Die politische Kultur des antiken Rom und die Forschungen der letzten Jahrzehnte. München, 2004. [Reconstructing the Roman Republic: An Ancient Political Culture and Modern Research. Princeton (N. J.) 2010].

HUMER, Edith. Linkshändigkeit im Altertum. Zur Wertigkeit von links, der linken Hand und Linkshändern in der Antike. Tönning, 2006.

144 HUMM, Michel. Histoire culturelle et histoire sociale. Saeculum 60, 2010, p. 187-204.

JEHNE, Martin (ed.). Demokratie in Rom? Die Rolle des Volkes in der Politik der römischen Republik. Stuttgart 1995.

KANTOROWICZ, Ernst Hartwig. The King's Two Bodies. A Study in Mediaeval Political Theology. Princeton (N. J.), 1957.

KRAIS, Beate; GEBAUER, Günter. Habitus. 2nd ed. Bielefeld, 2008.

LORENZ, Maren. Leibhaftige Vergangenheit. Einführung in die Körpergeschichte. Tübingen, 2000.

LÜDTKE, Alf (ed.). Alltagsgeschichte. Zur Rekonstruktion historischer Erfahrungen und Lebensweisen. Frankfurt, 1989.

MARTIN, Jochen. Bedingungen menschlichen Handelns in der Antike. Gesammelte Beiträge zur historischen Anthropologie. Hrsg. von Winfried Schmitz. Stuttgart, 2009.

MAURITSCH, Peter (ed.). Körper im Kopf. Antike Diskurse zum Körper. Graz, 2010. MAUSS, Marcel. Les techniques du corps. Journal de Psychologie Normale et Pathologique 32, 1936, p. 271-293.

MEISTER, Jan B. Adventus und Provectio. Aristokratisches Prestige, Bindungswesen und Raumkonzepte im republikanischen und frühkaiserzeitlichen Rom. Museum Helveticum 70, 2013, p. 33-56. 
Der Körper des Princeps. Zur Problematik eines monarchischen Körpers ohne Monarchie. Stuttgart, 2012.

H. Review of Wirth, Die linke Hand: Wahrnehmung und Bewertung in der griechischen und römischen Antike (HABES), Stuttgart 2010. Museum Helveticum 68, 2011, p. $241 \mathrm{f}$.

- Pisos Augenbrauen. Zur Bedeutung aristokratischer Körper in der späten Republik. Historia 58, 2009, p. 71-95.

MEYER-ZWIFFELHOFFER, Eckhard. Im Zeichen des Phallus. Die Ordnung des Geschlechtslebens im antiken Rom. Frankfurt, 1995.

MOREAU, Philippe (ed.). Corps romains. Grenoble, 2002.

NIPPEL, Wilfried. Klientel, Gesellschaftsstruktur und politisches System in der römischen Republik. Humanistische Bildung 21/22, 2002, p. 137-151.

ORY, Pascal. L'histoire culturelle. 2nd ed. Paris, 2007.

PORTER, James I. (ed.). Constructions of the Classical Body. Ann Arbor, 1999.

POST, Francis; WILGAUX, Jérôme (eds.). Penser et représenter le corps dans I'Antiquité. Rennes, 2006.

ROLLeR, Matthew. Dining Posture in Ancient Rome. Bodies, Values, and Status. Princeton (N. J.), 2006.

SARASIN, Philipp. Mapping the body. Körpergeschichte zwischen Konstruktivismus, Politik und "Erfahrung". Historische Anthropologie 7, 1999, p. 437-451.

SCHMITZ, Winfried. ÜberGrenzenhinweg. Neuesozial-und kulturwissenschaftliche Ansätze in der Alten Geschichte. Saeculum 60, 2010, p. 205-225.

SCHNURBUSCH, Dirk. Convivium. Form und Bedeutung aristokratischer Geselligkeit in der römischen Antike. Stuttgart, 2011.

SPÄTH, Thomas. Männlichkeit und Weiblichkeit bei Tacitus. Zur Konstruktion der Geschlechter in der römischen Kaiserzeit. Frankfurt, 1994.

. Nouvelle histoire ancienne? Sciences sociales et histoire romaine: à propos de quatre récentes publications allemandes. Annales. Histoire, Sciences Sociales 54/5, 1999, p. 1137-1156.

STÄHLI, Adrian. Die Körper und seine Bilder: Nacktheit, der männliche Körper und das männliche Begehren in Bildern des 6. und 5. Jahrhunderts v. Chr., Habil. Zürich, 2002 (unpublished) [non vidi].

STARBATTY, Angelika. Aussehen ist Ansichtssache. Kleidung in der Kommunikation der römischen Antike. München, 2010.

STEIN-HÖLKESKAMP, Elke. Das römische Gastmahl. Eine Kulturgeschichte, München, 2005. 
SWAIN, Simon (ed.). Seeing the Face, Seeing the Soul. Polemon's Physiognomy from Classical Antiquity to Medieval Islam. Oxford, 2007.

THOMMEN, Lukas. Antike Körpergeschichte. Zürich, 2007.

TSCHOPP, Silvia Serena; WEBER, Wolfgang E. J. (eds.). Grundfragen der Kulturgeschichte. Darmstadt, 2007.

(ed.). Kulturgeschichte. Basistexte. Stuttgart, 2008.

. Einleitung. Begriffe, Konzepte und Perspektiven der Kulturgeschichte. In: (ed.). Kulturgeschichte. Basistexte. Stuttgart, 2008a, p. 9-32.

VOGT, Sabine. Aristoteles. Physiognomonica. Übersetzt und kommentiert (= Aristoteles, Opuscula VI). Berlin, 1999.

VÖSSING, Konrad (ed.). Das römische Bankett im Spiegel der Altertumswissenschaften. Stuttgart, 2008.

WEHLER, Hans-Ulrich. Die Herausforderung der Kulturgeschichte. München, 1998.

WILLIAMS, Craig A. Roman Homosexuality. Ideologies of Masculinity in Classical Antiquity. 2nd ed. 2010. New York and Oxford, 1999.

WINTERLING, Aloys. Review of Dirk Barghop, Forum der Angst. Eine historischanthropologische Studie zu Verhaltensmustern von Senatoren im 146 römischen Kaiserreich, Frankfurt, 1994. Klio 82, 2000, p. 272-274. (ed.). Historische Anthropologie. Basistexte. Stuttgart, 2006. . Freundschaft und Klientel im kaiserzeitlichen Rom. In: Historia 57, 2008, p. 298-316 [= Politics and Society in Imperial Rome. Malden etc., 2009, p. 34-57].

WIRTH, Henning. Die Linke Hand. Wahrnehmung und Bewertung in der griechischen und römischen Antike. Stuttgart, 2010.

WYKE, Maria (ed.). Parchments of Gender. Deciphering the Bodies of Antiquity. Oxford, 1998. 